\title{
Considering the Significance of Food Insecurity and Nutrition in New
} Brunswick Communities

\section{Chris W. Ashton}

Health Consulting Division, HarbourFront Health Group, Canada

\section{Introduction}

Recent data gathered by the New Brunswick Health Council [1] speaks to a significant prevalence of food insecurity (often $7 \%$ prevalence) and poor nutritional practices within many communities in New Brunswick. In terms of food insecurity, in addition to the experience of hunger, community members have reported that affected families are also forced to consume poor nutrition food. The high cost of high nutrition, locally available food represents a barrier to healthy eating for many community members and families. Local consultation with the food banks also speaks to a much less than optimal food quality being distributed to meet the basic needs of families serviced.

This paper speaks to the likelihood of poor nutrition food and insecurity creating significant current and downstream negative health impacts. From the perspective of children and youth, developmental delays are argued to be a direct consequence of poor nutrition, leading to a negative cascade of poor learning, cognitive and emotional deficits, all pointing to more difficulties and less fulfilling adults lives. Three common issues encountered with poor nutrition are diabetes mellitus [2], iron and Vitamin D deficiencies; in addition to contributing to chronic disease, daily levels of functioning and productivity are argued to be impaired among children and adults alike.

Evidence strongly supporting interventions currently at work with New Brunswick communities such as prenatal programs and school breakfast programs is also given in this paper. An indication of the significant benefits given the relatively low cost of such programs is provided to inform continued and improved support to these programs.

\section{Discussion}

The World Health Organization (WHO) in 2005 [3] predicted that chronic diseases would account for $80 \%$ of all deaths in Canada. The WHO speaks to this further from a prevention perspective:

"At least 80\% of premature heart disease, stroke and type 2 diabetes, and $40 \%$ of cancer could be prevented through healthy diet, regular physical activity and avoidance of tobacco products. Cost-effective interventions exist: the most successful strategies have employed a range of populationwide approaches combined with interventions for individuals."

It has been reported for nearly 20 years that brain development (including in utero) is clearly linked with nutrition. It has also been known since the mid-nineties that school feeding programs not only increase attendance, academic achievement levels are also higher. School feeding programs erase the disadvantages that young children experience when they grow up in marginalized neighbourhoods characterized by poverty, hunger and malnutrition, broken families and crime [4].

Ten years ago, another study found that better nourished children perform significantly better in school, mostly because of greater learning productivity per year of schooling [5]. A cost-benefit analysis suggests that a dollar invested in an early childhood nutritionprogram could potentially return at least three dollars' worth of gains in academic

\section{Publication History:}

Received: October 27, 2014

Accepted: December 23, 2014

Published: December 25, 2014

achievement, and perhaps much more. Similar long term studies have demonstrated similar findings with cost benefit ratios of 1:1.5 to 1:6 [6].

Prenatal nutrition programs that targeted low income, high risk pregnancies in Montreal have been shown to improve long term health outcomes in children, saving at least $\$ 8$ for each dollar invested [7]. This program works with individual pregnant mothers through a dietician risk assessment and development of a rehabilitative nutritional diet. The Canadian Prenatal Nutrition Program (CPNP) has shown considerable success nationally in reducing the incidence of low birth weight (LBW) infants and in increasing the proportion of mothers who breastfeed their infants. This in turn, has been shown to decrease the incidence of failure to thrive (FTT) infants and respiratory illnesses, conditions endemic to and the cause of considerable disability among low income Canadians $[7,8]$.

Colon cancer is one of the most common forms of cancer seen among adult males. Prevention of this cancer has been demonstrated to be most amenable to nutritional and dietary therapy. For the aggregate of cancer cases, a reduction of one third of cases can be achieved through healthy diet and lifestyle choices [8].

Population health promotion strategies that address healthy eating and active lifestyles have been shown of benefit in reducing the incidence and severity of chronic disease. Studies of primary healthcare interventions that involved nutrition demonstrated positive results and support the individual interventions involving skilled nutrition educators. Risks for cardiovascular disease including dyslipidemia and hypertension have been demonstrated to be substantially reduced through dietary intervention [9-13].

Diabetes poses a serious health concern for a large proportion of the Canadian population. Lifestyle interventions by dietitians have been shown to reduce the risk of developing diabetes by $58 \%$ and benefits remain following completion of specific care. Additionally, educational care given by dietitians to diabetics has been shown to be more cost effective than management by medications [13].

Also highly relevant to New Brunswick, dietary intervention has been shown to substantially improve mental health outcomes $[14,15]$. Poverty and food insecurity among New Brunswickers is recognized

"Corresponding Author: Dr. Chris W. Ashton, Health Consulting Division, Harbour Front Health Group, Canada; E-mail: chrisashton@hfhg.ca

Citation: Ashton CW (2014) Considering the Significance of Food Insecurity and Nutrition in New Brunswick Communities. Int J Diabetes Clin Diagn 1: 108. doi: http://dx.doi.org/10.15344/2394-1499/2014/108

Copyright: () 2014 Ashton. This is an open-access article distributed under the terms of the Creative Commons Attribution License, which permits unrestricted use, distribution, and reproduction in any medium, provided the original author and source are credited. 
to be an endemic problem for which ongoing strategies and initiatives are being designed and implemented. This will require a long term effort given the complexities and costs of nutritious food availability. Food insecurity consequences are further intensified by the relatively low costs associated with low nutritional value, high fat and carbohydrate foods (junk food). Good evidence exists regarding nutrition support both at the policy and client level to increase food intake in food insecure households and communities [16,17]. In simple terms, nutritionists and health promotion specialists may act as effective advocates in addressing food insecurity to decision makers, create population based solutions to mitigate the nutrition impacts and work individually with clients and other care givers to optimize nutrition intake in the context of food insecurity.

Obesity remains a growing epidemic among Canadians and New Brunswickers. The correlation with other chronic diseases and the socioeconomic impact is well documented [14,17]. For this problem, medical interventions have not yet been shown effective. Rather, for treatment of overweight and obese people, a multidisciplinary approach employing nutritional therapy delivered by dieticians is recognized as a best practice in this regard [17].

A prevalence of Vitamin D and iron deficiency associated with food insecurity may well be indicative of ominous, chronic health issues adversely impacting child development, healthy pregnancies, population well-being and life expectancy of New Brunswickers.

Regarding Vitamin D hypovitaminosis, this condition is associated with $[6,7]$ :

- Increased risk for rickets, adult hip fractures.

- Increased risk for and increased mortality rates for colon cancer.

- Increased risk for and increased mortality rates for breast cancer.

- Increased risk for and increased mortality rates for cardiovascular disease.

- Increased prevalence of diabetes and multiple sclerosis.

- $\quad$ several bacterial and viral infections including respiratory and otolaryngologic.

- Reasonable evidence of a beneficial role of vitamin D exists for about 16 types of cancer colon, esophageal, gallbladder, gastric, pancreatic, rectal; urogenital: bladder, kidney, and prostate; female: breast, endometrial, ovarian, and vulvar cancer; and blood cancers: Hodgkin's lymphoma, non-Hodgkin's lymphoma, and multiple myeloma).

On a national basis, it has been estimated that the death rate could fall by 37000 deaths (22 300-52 300 deaths), representing 16.1\% (9.7$22.7 \%)$ of annuals deaths and the economic burden by $6.9 \%$ (3.8$10.0 \%$ ) or $\$ 14.4$ billion ( $\$ 8.0$ billion- $\$ 20.1$ billion) less the cost of the program [6]. European studies have also shown positive cost benefits for Vitamin D therapeutic interventions [7]. Given the significant prevalence of food insecurity and poor nutritional practices in New Brunswick, positive economic benefits of addressing this issue may be expected to be highly significant.

Regarding iron deficiency, this condition is associated with $[18,19]$ :

- poor pregnancy outcomes.

- poor motor and mental performance in children.

- low work productivity.
In a study on the economic benefits of iron fortification in 10 countries, the cost benefit median ratio is $6: 1$ for the 10 countries examined and rises to $36: 1$ including the discounted future benefits attributable to cognitive improvements. These benefits were calculated solely on the basis of economic implications of motor and mental impairment in children and low work productivity in adults. Other implications, such as costs associated with complications in pregnant and postpartum mothers, were not available [18].

Additional literature suggests the most cost effective approach to alleviating iron deficiency is through food based approaches [19]. Given the likely high levels of iron deficiency and associated conditions among New Brunswickers, interventions aimed at remedying this condition could be expected to be highly significant.

The importance of good nutrition and the role of dietitians in institutionalized care are well documented. Nutrition intervention on malnourished patients has demonstrated a twofold beneficial effect on health of the patient and healthcare system budget. Firstly, oral nutrition supplement (ONS) interventions allow malnourished patients to gain weight [20], and to improve their functional status such as activity of daily living (ADL) or muscle strength [21]. Secondly, in hospitalized malnourished patients, nutritional intervention has been shown to reduce mortality by $24 \%$, complications rate by $56 \%$ and length of hospital stay by 2 days in surgical patients to 33 days in orthopaedic patients [22]. In addition, high protein ONS given to acutely ill older people lowers the number of patients readmitted to hospital at six months [23].

In 1997, Smith and Smith [24] in a survey of hospital practices on nutrition screening and intervention demonstrated that for every \$1USD spent on provision of high-quality nutritional care, it resulted in a \$5USD savings for the facility.

\section{Conclusion}

"Food security exists when all people, at all times, have physical and economic access to sufficient, safe and nutritious food to meet their dietary needs and food preferences for an active and healthy life" [25]. Information gathered to date through the Community Health Needs Assessments (CHNA) in New Brunswick indicates that the prevalence of food security across and within communities is far from uniformly assured. Given the health outcome data gathered for New Brunswick, there are few conditions that cannot be linked in some form or manner to the quality, quantity and nutritional value of food consumed within this province. Food security is considered one of the most predictive social determinants of health and is directly linked to other determinants including income. Information provided in this brief review, while far from comprehensive, may assist decision makers and community members in their prioritization process to address community health needs.

\section{Competing Interests}

The authors declare that they have no competing interests.

\section{References}

1. New Brunswick Health Council (2011) Primary Health Care Survey.

2. Gucciardi E, Vogt J, DeMelo M, Stewart D (2009) exploration of the relationship between household food insecurity and diabetes mellitus in Canada. Diabetes Care 32: 2218-2224.

3. WHO (2005) Facing the Facts: The Impact Of Chronic Disease In Canada 
Citation: Ashton CW (2014) Considering the Significance of Food Insecurity and Nutrition in New Brunswick Communities. Int J Diabetes Clin Diagn 1: 108. doi: http://dx.doi.org/10.15344/2394-1499/2014/108

4. World Bank, The Benefits of Early Childhood Development Programs, An Economic Analysis.

5. Glewwea P, Jacobya HG, Kinga EM (2001) Early childhood nutrition and academic achievement: a longitudinal analysis. J Public Eco 81: 345-368.

6. Bauer PJ (2011) Monographs of the Society for Research in Child Development. Econ Analysis 79.

7. Dieticians of Canada (2011) Pan Territorial Dietetic Internship - An Environmental Scan.

8. Grant WB, Schwalfenberg GK, Genuis SJ, Whiting SJ (2010) An estimate of the economic burden and premature deaths due to vitamin $D$ deficiency in Canada. Mol Nutr Food Res 54: 1172-1181.

9. Grant WB, Cross HS, Garland CF, Gorham ED, Moan J, et al. (2009) Estimated benefit of increased vitamin D status in reducing the economic burden of disease in western Europe. Prog Biophys Mol Biol 99: 104-113.

10. World Cancer Research Fund. Food, Nutrition, Physical Activity and the Prevention of Cancer: A Global Perspective.

11. McPherson R, Frohlich J, Fodor G, Genest J (2006) Canadian Cardiovascular Society position statement - Recommendations for the diagnosis and treatment of dyslipidemia and prevention of cardiovascular disease. Can J Cardiol 22: 913-927.

12. Howlett JG, McKelvie RS, Arnold JM, Costigan J, Dorian P (2009) Canadian Cardiovascular Society Consensus Conference guidelines on heart failure, update 2009: Diagnosis and management of right-sided heart failure, myocarditis, device therapy and recent important clinical trials. Can J Cardiol 25: 85-105.

13. Kris-Etherton P, Daniels SR, Eckel RH, Engler M, Howard BV, et al. (2001) AHA scientific statement: summary of the Scientific Conference on Dietary Fatty Acids and Cardiovascular Health. Conference summary from the Nutrition Committee of the American Heart Association. J Nutr 131: 13221326 .

14. Herman WH, Hoerger TJ, Brandle M, Hicks K, Sorensen S, et al. (2005) The cost-effectiveness of lifestyle modification or metformin in preventing type 2 diabetes in adults with impaired glucose tolerance. Ann Intern Med 142: 323-332.

15. Pong RW, DesMeules M, Heng D, Lagacé C, Guernsey JR, et al. (2011) Patterns of health services utilization in rural Canada. Chronic Dis Inj Can 31 Suppl 1: 1-36

16. The World Bank, Benefits of Early Child Development Programs.

17. Dieticians of Canada, Moving Forward - Role of the Registered Dietician in Primary Health Care - A National Perspective.

18. Power E; Dietitians of Canada (2005) Individual and household food insecurity in Canada: position of Dietitians of Canada. Can J Diet Pract Res 66: 43-46.

19. Horton, S, Ross J (2003) The economics of iron deficiency. Food Policy 28: 51-75.

20. Hunt JM (2002) Reversing productivity losses from iron deficiency: the economic case. J Nutr 132: 794S-801S

21. Milne AC, Potter J, Vivanti A, Avenell A (2009) Protein and energy supplementation in elderly people at risk from malnutrition. Cochrane Database Syst Rev.

22. Norman K, Pichard C, Lochs H, Pirlich M (2008) Prognostic impact of disease-related malnutrition. Clin Nutr 27: 5-15.

23. Stratton RJ, Green CJ, Elia M (2004) Disease-related malnutrition: an evidence based approach to treatment Am J Clin Nutr 79:1128-1129.

24. Gariballa S, Forster S, Walters S, Powers H. (2006) A randomized, doubleblind, placebo-controlled trial of nutritional supplementation during acute illness. Am J Med 119: 693-699.

25. Smith PE, Smith AE (1997) High-quality nutritional interventions reduce costs. Healthc Financ Manage 51: 66-69. 